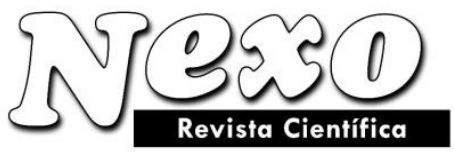

\title{
BIORREMEDIACIÓN DE SUELOS CONTAMINADOS POR ORGANOCLORADOS MEDIANTE LA ESTIMULACIÓN DE MICROORGANISMOS AUTÓCTONOS, UTILIZANDO BIOSÓLIDOS
}

\section{BIORREMEDIATION OF SOILS CONTAMINATED BY ORGANOCLORATED BY THE STIMULATION OF AUTOCONAL MICROORGANISMS, USING BIOSOLIDS}

\author{
L.F. Durán Acosta ${ }^{1, *}$, M.J. Ladera Hernández ${ }^{1 .}$ \\ Universidad Nacional de Ingeniería. Programa de Investigación, Estudios Nacionales y Servicios \\ Ambientales (PIENSA). Maestría en Ciencias Ambientales. Managua, Nicaragua. \\ luisaduran8686@hotmail.com.
}

\begin{abstract}
RESUMEN
La presente investigación evaluó el proceso de biorremediación de plaguicidas organoclorados en un suelo del aeródromo agrí́cola "El Picacho" del Departamento de Chinandega, Nicaragua, en el que se registran grandes concentraciones de toxafeno. Se empleó la técnica de bioestimulación en el proceso de biorremediación, utilizando biosólidos como fuente de nutrientes esenciales para los microorganismos. El diseño experimental constó de 2 bloques completamente aleatorizados, cada uno con 3 unidades experimentales, contemplando 6 microcosmos de suelo. A cada tratamiento se agregó diferentes proporciones de biosólido estableciendo relaciones suelo: biosólido de 71:29 y 77:23. Al finalizar los tratamientos se obtuvieron porcentajes de remediación entre $84 \%$ y $69 \%$ respectivamente. Esto evidencia la efectividad de los biosólidos como fuente de nutrientes para la estimulación metabólica de microorganismos autóctonos en el proceso de biorremediación de suelos contaminados con toxafeno.
\end{abstract}

Palabras claves: Bioestimulación, Biorremediación, Biosólidos, Organoclorados, Plaguicidas, Toxafeno.

\begin{abstract}
The present investigation evaluated the process of bioremediation of organochlorine pesticides in a soil of the agricultural airport "The Picacho" of Chinandega's Department, Nicaragua, in that there are registered big concentrations of toxafeno. The biostimulation technique was used in the bioremediation process, using biosolids as source of essential nutrients for the microorganisms. The experimental design consisted of 2 completely randomized blocks, each one with 3 experimental units, contemplating 6 microcosms of soil. To every treatment one added different proportions of biosolids establishing relations soil:biosolid of 71:29 and 77:23. On having finished the treatments percentages of remediation were obtained between $84 \%$ and $69 \%$ respectively. This demonstrates the efficiency of the biosolids as source of nutrients for the metabolic stimulation of autochthonous microorganisms in the process of bioremediation of soils contaminated with toxafeno.
\end{abstract}

Keywords: Biostimulation, Bioremediation, Biosolids, Organochlorine, Pesticides, Toxafeno. 


\section{INTRODUCCIÓN}

Actividades como la agricultura, han incrementado los últimos años el número de suelos afectados por el uso de plaguicidas, ocasionando impactos severos a los recursos acuáticos e incluso a la salud humana. Ante esta situación actualmente se han desarrollados alternativas para mitigar este impacto y técnicas como la biorremediación, resultan una alternativa económica y viable en la que los microorganismos son la herramienta más importante en el proceso de descontaminación, ya que estos hacen uso del contaminante como fuente de energía para su metabolismo, disminuyendo la disponibilidad del mismo en los suelos afectados, en este sentido; la bioestimulación permite activar el potencial degradativo que poseen los microorganismos en el proceso de remediación, (Álvarez, 2007), en su estudio; "utilizacion de fangos digeridos en el proceso de biorremediacion de residuos sólidos petrolizados", en el que aplicó la técnica de bioestimulacion de microorganismos para disminuir la carga de hidrocarburo en el suelo, logrando reducir a $1 \%$ la concentración del contaminante en un periodo de 80 días. De igual forma, (Araujo et al, 2007), evaluron en su trabajo "incorporación de lodos estabilizados en el proceso de biorremediación de suelos afectados con hidrocarburos", la eficiencia de la técnica, encontrando que los ensayos que contenían la fracción de lodos, mostraban una correlación significativa entre el porcentaje final de hidrocarburo y el crecimiento bacteriano. Por su parte, (Reyes et al, 2006), realizaron en Colombia el estudio sobre la biodegradación de organoclorados-aldrin a partir de cepas aisladas de un consorcio bacteriano aerobico; en el estudio, cada sepa se expuso individualmente a 0,15 y 30 dias en un medio de sales acondicionadas y $60 \mathrm{mg} / \mathrm{l}$ de aldrin, al terminar el estudio se comprobó que las cepas no solo toleraron la concentración de aldrin sino que fueron capaces de degradarlo.

En todo estudio de biorremediación, en el que se estime hacer uso de la técnica de aumentación, se requiere la incorporación de nutrientes esenciales que garanticen el desempeño microbiano. En consecuencia, es imprescindible conocer, valorar y controlar las características físico-químicas del material utilizado como estimulante y del suelo en estudio, a tales efectos; se debe considerar la humedad, $\mathrm{pH}$, nitrógeno, materia orgánica disponible, fosforo, coliformes y el propio contaminante. Para efectos del estudio, los análisis físico-químicos y micóticos del suelo y el biosólido, fueron realizados en el laboratorio de suelos, micología y microbiología de la Universidad Nacional Agraria (UNA). Mientras que la determinación de coliformes fecales, fue realizada en el laboratorio de microbiología del CIEMA-UNI, dando cumplimiento a las normativas de incorporación de biosólidos en suelos establecidas por la EPA y lograr el objetivo de remediación del suelo contaminado con toxafeno.

En el estudio la estimularon los microorganismos autóctonos presentes en suelos afectados, se realizó mediante la aplicación de biosólidos producto del tratamiento de aguas residuales domésticas; esto proporciona además, una alternativa para el manejo ambiental de este tipo de material, cuya disposición final resulta una problemática ambiental en la mayoría de las poblaciones.

\section{METODOLOGÍA}

Para efectos del estudio, se contó con muestras de suelos establecidos en bloques de tratamiento, bajo condiciones controladas, constituidos de la siguiente manera:

\subsection{Universo de Estudio}

Estuvo representado por 6 microcosmos de suelos contaminados con organoclorados, proveniente del aeródromo agrícola El Picacho del Departamento de Chinandega, municipio El Viejo; lugar de carga, descarga y prueba de bombeo de avionetas para la fumigación de cultivos a mediados de 1990, actividad que actualmente se sigue practicando en menor proporción. Los suelos, fueron dispuestos en pilas de concretos de $1 \mathrm{~m}^{2}$ y profundidad de $30 \mathrm{~cm}$, ubicadas a la intemperie en las inmediaciones de la planta de

Nexo Revista Científica / Vol. 29, No. 01, pp. 22-28 / Junio 2016 


\section{L.F. Durán-Acosta y M.J. Ladera Hernández}

tratamiento de suelos de la empresa Enviromental Protection \& Control (EPC) ubicada en San Benito en el km 33.5 de la carretera Panamericana Norte, de Nicaragua, con el propósito de simular las condiciones ambientales a las que normalmente estarían sometidas las muestras de suelos para efectos del tratamiento.

\subsection{Muestreo de suelo}

Se llevó a cabo un muestreo de 5 transeptos, en zigzag a los laterales de la pista del aeródromo "El Picacho", con una profundidad comprendida entre los 30-70 cm. Las muestras fueron tomadas a intervalos regulares a lo largo de la pista con una distancia aproximada de 120 metros, posteriormente fueron mezcladas hasta homogeneizar, procediendo a conformar 6 microcosmos de suelo contaminado.

\subsection{Muestreo de biosólidos}

Las muestras de biosólidos, fueron tomadas de la planta de tratamiento de aguas residuales domésticas del conjunto residencial Ciudad Real en Veracruz, Managua, Nicaragua. Dicho material, fue previamente estabilizado en la planta mediante la aplicación de cal, y deshidratado mediante la acción solar. El muestreo se realizó en forma de zigzag, considerando para ello 6 puntos de muestreo en el área de extensión del material, seguidamente las muestras fueron homogeneizadas para su aplicación en los microcosmos de suelos contaminados.

\subsection{Etapas de monitoreo del ensayo}

Una vez establecido el experimento se llevó a cabo un monitoreo diario de los parámetros correspondientes a humedad y temperatura, mientras que el $\mathrm{pH}$ fue evaluado dos días por semana, esto a manera de darle seguimiento al mantenimiento de los parámetros que debe seguir un proceso de biorremediación. Para verificar el comportamiento del tratamiento, se colectaron muestras de suelo a los 0 y 73 días de establecido el experimento, a las cuales se les evaluó el aumento o disminución de los microorganismos, bioindicadores del proceso de biorremediación y la concentración de organoclorado.

\subsection{Diseño y unidad experimental}

Se dispuso de un ensayo conformado por 6 parcelas o unidades experimentales distribuidas en 2 bloques, sobre los cuales se realizaron los tratamientos. Cada bloque contó con una unidad cuyo factor determinante fue la ausencia o presencia del biosólido en diferentes cantidades. Quedando conformado por; Bloques IA y II A: con $125 \mathrm{~kg}$ de suelo contaminado sin biosólidos (controles), para las unidades de los bloques IB y II B se incorporó $125 \mathrm{~kg}$ de suelo contaminado representando el $71 \%$ y $50 \mathrm{~kg}$ de biosólidos correspondiente al $29 \%$ de la totalidad de la mezcla, estableciendo una relación porcentual de 71:29. Por su parte, en los tratamientos IC y II C, la relación porcentual establecida fue de 77:23 siendo $125 \mathrm{~kg}(77 \%)$ de suelo contaminado y $37 \mathrm{~kg}(23 \%)$ de biosólido respectivamente. Al biosólido le fue aplicado un tratamiento térmico en el que se sometió a una temperatura de $221^{\circ} \mathrm{C}$ durante 45 minutos en autoclave, a fin de disminuir la carga de patógenos determinada con los análisis realizados de coliformes fecales.

\subsection{Análisis experimental}

Durante el estudio, se efectuaron estudios de evaluación y control de las unidades de tratamiento, utilizando metodologías diversas según las características de evaluación:

Determinación de la concentración de organoclorados en las muestras de suelo: las muestras fueron analizadas por el Laboratorio de Residuos Biológicos del Ministerio Agropecuario y Forestal (MAGFOR). Se procedió a realizar la extracción pesando 10 gr de suelo sin secar y tamizado en un matraz erlenmeyer de $250 \mathrm{ml}$, en el cual se agregó $7 \mathrm{ml}$ de solución $0.2 \mathrm{M}$ de $\left(\mathrm{NH}_{4} \mathrm{Cl}\right)$, Se añadió $100 \mathrm{ml}$ de hexano-acetona (1+1), se tapó y dejó en agitación durante toda la noche. Con el fin de eliminar los

Nexo Revista Científica / Vol. 29, No. 01, pp. 22-28 / Junio 2016 


\section{L.F. Durán-Acosta y M.J. Ladera Hernández}

coextractos que pudieran interferir en una buena resolución del análisis cromatográfico, se limpió el extracto con una columna de florisil, se realizó un enjuague del suelo con dos porciones de hexanoacetona y se decantó a través de la columna, Se agregaron $200 \mathrm{ml} \mathrm{de} \mathrm{H}_{2} \mathrm{O}$ al separador agitando vigorosamente por 30 segundos para luego drenar la fase acuosa en un segundo separador extrayendo con $50 \mathrm{ml}$ de hexano. Se combinaron las capas de hexano en el primer separador y se lavó con $100 \mathrm{ml} \mathrm{de} \mathrm{H}_{2} \mathrm{O}$. $\mathrm{El} \mathrm{H}_{2} \mathrm{O}$ fue drenada y desechada y el hexano se pasó a través de la columna con $2 \mathrm{~cm}$ de sulfato de sodio anhidro $\left(\mathrm{Na}_{2} \mathrm{SO}_{4}\right)$, concentrando a $100 \mathrm{ml}$. Posterior a esto se realizó la inyección de 5 a $10 \mu \mathrm{l}$ en el cromatógrafo de gases marca Agilent modelo 7890A, con columna capilar BD 1701, 30m x 0.32mm x $0.25 \mu \mathrm{m}$ y detector $\mu \mathrm{EC}$. Obteniendo los resultados que se muestran en la Tabla 2.

Caracterización físico-química y microbiológica de las muestras de suelo: efectuados en las instalaciones de la Universidad Nacional Agraria (UNA), mediante el método de dilución seriada (Castaño-Zapata, 1986), el cual consistió en pesar $10 \mathrm{gr}$ de suelo diluidos en $90 \mathrm{ml}$ de agua destilada, una vez en reposo por 5 min (dilución $1: 10^{-2}$ ), se transfirió $1 \mathrm{ml}$ a un tubo de ensayo con $9 \mathrm{ml}$ de agua destilada estéril mezclándose bien $\left(10^{-3}\right)$, de manera análoga se transfirió la dilución hasta completar concentraciones de $10^{-6}$. De la dilución $10^{-4}$ se sembraron $0.2 \mathrm{ml}$ en medio PDA (papa, dextrosa, agar), medio general para hongos; de la dilución $10^{-6}$ se sembraron $0.2 \mathrm{ml}$ en medio AN (agar nutritivo) para bacterias y medio AA (medio general para hongos) utilizado para actinomycetes, la siembra se realizó a través de la técnica de Drigalski. Para cuantificar las poblaciones de hongos, bacterias y actinomicetos de suelo, se utilizó la metodología consistente en cuantificar las unidades formadoras de colonias (UFC), (Sergueichuck, 1986), para ello se utilizaron seis repeticiones por muestra de suelo en las diferentes capsulas de petri. Para la identificación de bacterias se utilizó criterios morfológicos (forma, tinción de Gram, movilidad y pigmentación), bioquímicos (prueba de oxidación). La identificación de los hongos se hizo mediante la clave (Barnett y Hunter, 1999). Según los datos obtenidos a partir de las metodologías aplicadas, las características del material en estudio se corresponden con las señaladas en la Tabla 1.

Tabla 1. Características fisicoquímicas de suelo y lodo.

\begin{tabular}{|c|c|c|c|c|c|c|c|c|c|c|c|}
\hline & $\mathrm{pH}$ & MO & $\mathbf{N}$ & $\mathbf{P}$ & K-d & $\mathbf{K}$ & $\mathbf{C a}$ & $\mathbf{M g}$ & $\mathbf{N a}$ & CIC & Tex \\
\hline & & $\%$ & $\%$ & ppm & & & & & & & \\
\hline & & & & & \multicolumn{7}{|c|}{$\mathrm{Mg} / 100 \mathrm{~g}$ suelo } \\
\hline Lodo & 6.49 & 9.1 & 0.45 & 267 & 1.92 & 4.39 & 30.22 & 11.36 & 6.46 & 56.96 & $\begin{array}{l}\text { Arc- } \\
\text { A }\end{array}$ \\
\hline Suelo & 5.64 & 2.32 & 0.11 & 25.6 & 0.66 & 0.77 & 10.02 & 1.55 & 0.40 & 14.99 & $\mathrm{Fr}$ \\
\hline
\end{tabular}

$\mathrm{pH}=$ acidez o alcalinidad; $\mathrm{MO}=$ materia orgánica; $\mathrm{N}=$ nitrógeno; $\mathrm{P}=$ fosforo; $\mathrm{K}-\mathrm{d}=$ potacio disponible $; \mathrm{Ca}=$ calcio; $\mathrm{Mg}=\mathrm{magnesio} ; \mathrm{Na}=$ sodio; $\mathrm{CIC}=$ capacidad de intercambio catiónico; Tex= textura; Arc-A= arcilloso arenoso; $\mathrm{Fr}=$ franco.

Caracterización microbiológica de biosólidos: La determinación de coliformes fecales fue realizada al inicio y final del estudio, en el laboratorio de microbiología del CIEMA-UNI, a través de la metodología analítica 9221E, (Standard Methods for the examination of water and wastewater, 2005), mediante la técnica de fermentación de tubos múltiples para la determinación del número más probable (NPM) de organismos coliformes. El método consistió en la determinación de la densidad de coliformes y se realizó en dos etapas: la prueba presuntiva y la prueba confirmativa, en la prueba presuntiva, la actividad metabólica de las bacterias fue estimulada vigorosamente ocurriendo una selección densa de los organismos que utilizaron la lactosa después de la incubación a $35.5{ }^{\circ} \mathrm{C} \pm 0.5{ }^{\circ} \mathrm{C}$ de 24 a 48 horas. Un cultivo de cada tubo gas-positivo en la prueba presuntiva, se transfirió a un tubo de medio EC a $44.5{ }^{\circ} \mathrm{C} \pm$ $0.2{ }^{\circ} \mathrm{C}$ para coliformes fecales, con un periodo de 24 horas de incubación en baño de maría. Luego del periodo de incubación, los tubos se agitaron suavemente y se observó la producción de gases. La presencia de gas fue considera como prueba positiva. El cálculo de NMP se basó en la combinación de tubos positivos y negativos; los resultados se reportan como NMP por 100ml (NMP/100 ml), según se indica en la ecuación 1. 
$N M P / 100 \mathrm{ml}=\quad \underline{N^{\circ} \text { tubos }(+) \times 100 \mathrm{ml}}$

Vol. muestras en tubos (-) $x$ Vol. muestras en total tubos

\section{RESULTADOS Y DISCUSIÓN}

El análisis cromatográfico realizado a las muestras de suelo, permitió constatar que la misma solo contenía el organoclorado denominado "toxafeno" en concentraciones de 343 ppm (343 mg/l o mg/kg), lo que supera el límite permisible de lixiviados en suelos según lo establecido en la normativa ambiental de diversos países, para efectos del estudio, se consideró el decreto 2.635 de la República Bolivariana de Venezuela, en el cual se contempla las normas para el control de la recuperación de materiales peligrosos y manejo de los desechos peligrosos, en el que establece como concentración máxima permitida de este contaminante valores igual o menor a $0.5 \mathrm{mg} / \mathrm{l}$.

Tal como se muestra en la Tabla 2, la incorporación del biosólido permitió disminuir significativamente la concentración del toxafeno en las unidades experimentales, mostrando porcentajes de eficiencias por encima del 70\%. Dichos resultados, permiten afianzar lo reportado por (Álvarez, 2007), en el cual se logra un elevado porcentaje de biorremediación de hidrocarburos haciendo uso de biosólidos, al resultar éstos la fuente de adición de elementos como nitrógeno y fósforo esenciales para el crecimiento microbiano.

Tabla 2. Concentración de organoclorados en muestras experimentales.

\begin{tabular}{|c|c|c|c|}
\hline Tratamientos & $\begin{array}{c}\text { A } \\
\text { valor promedio }\end{array}$ & $\begin{array}{c}\text { B } \\
\text { valor promedio }\end{array}$ & $\begin{array}{c}\mathrm{C} \\
\text { valor promedio } \\
\end{array}$ \\
\hline $\begin{array}{l}\text { Concentración } \\
\text { inicial (ppm) }\end{array}$ & 343 & 343 & 343 \\
\hline $\begin{array}{l}\text { Concentración } \\
\text { final (ppm) }\end{array}$ & 253 & 39.7 & 87.7 \\
\hline Factor de dilución & ------ & $\begin{array}{c}55.6 \\
F=1.4\end{array}$ & $\begin{array}{c}113.2 \\
F=1.29\end{array}$ \\
\hline $\begin{array}{l}\text { Porcentaje de } \\
\text { remoción }(\%)\end{array}$ & 25.1 & 88.6 & 74.4 \\
\hline
\end{tabular}

$\mathrm{A}=$ controles; $\mathrm{B}=$ tratamiento relación 71:29; $\mathrm{C}=$ tratamiento relación 77:23; $\mathrm{F}=$ factor de dilución aplicado.

Los valores de coliformes en el biosólido obtenidos inicialmente fueron de $10 \mathrm{x}^{7} \mathrm{NMP}$, por consiguiente este fue sometido a tratamiento térmico en una autoclave logrando obtener colonias de 10x6 NMP, ajustándose a la clasificación de clase B, que según lo establecido en la norma 503 de la EPA, pueden ser empleados como fertilizantes o mejoradores de suelos. Al finalizar el ensayo se evaluó el material resultante, obteniendo lodos de clase A, el cual de acuerdo con lo estipulado por la EPA, puede aplicarse sin restricciones alguna en los suelos (Guzmán y Campos, 2004). Ver Figura 1.

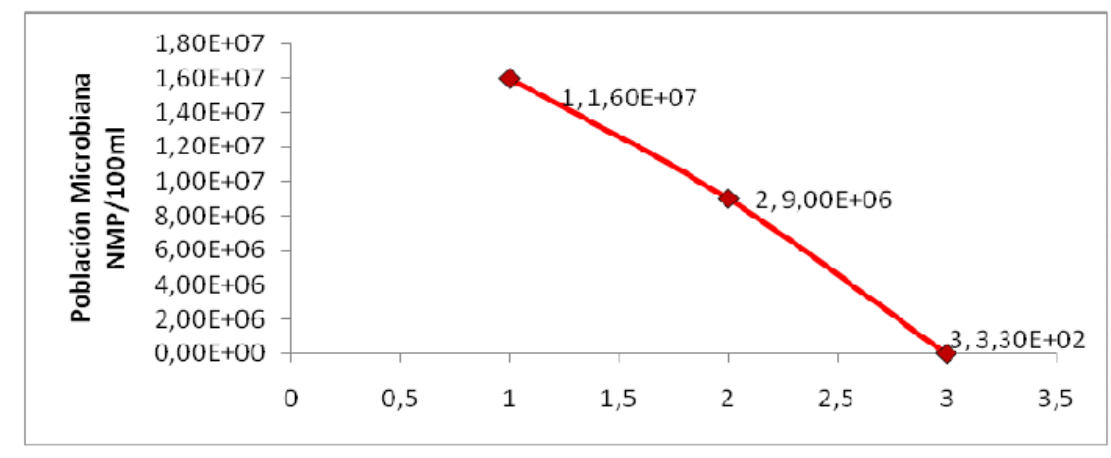

1= bisólido crudo; 2 = biosólido autoclavado; 3 = mezcla biosólido/suelo

Figura1. Representación de Coliformes en las muestras de suelo.

Nexo Revista Científica / Vol. 29, No. 01, pp. 22-28 / Junio 2016 
En cuanto al crecimiento microbiano, los estudios realizados a las muestras permiten destacar bacterias y actinomicetos en mayor abundancia, (Reyes et al, 2006).

\section{CONCLUSIONES}

Según el triángulo textural, las características del suelo objeto de estudio es de tipo franco, esto permitió incrementar significativamente la viabilidad del proceso de biorremediación y garantizar el alcance de los objetivos planteados, en ese sentido, se evidenció la capacidad que poseen los microorganismos para alcanzar la degradación del toxafeno, contaminante organocrorado identificado en los suelos. El ensayo permitió además de disminuir la concentración del plaguicida, comprobar que el uso de los residuos (biosólidos) provenientes de las plantas de tratamientos de aguas residuales domésticas, una vez determinada sus características biofisicoquímicas, resultan de utilidad para la recuperación de espacios contaminados con este tipo de plaguicidas, permitiendo así dar una disposición final al biosólidos ambientalmente segura.

\section{REFERENCIAS}

Álvarez, J. (2007). Utilización de fangos digeridos en el proceso de biorremediación de residuos sólidos petrolizados. [Documento en línea]. Disponible en:

http://www.monografias.com/trabajos44/biorremediacion-residuos/biorremediacion-residuos.shtml.

Araujo, I., Montilla, M., Cárdenas, C., Herrera, L., Angulo, N. y Morillo, G. (2007). Lodos estabilizados y cepas bacterianas en la biorremediación de suelos contaminados con hidrocarburos. Revista Interciencia INCI v31 n.4 Caracas abr. Caracas, Venezuela. [Revista en línea]. Disponible en: http://www.scielo.org.ve/scielo.php?pid=S0378-18442006000400006\&script=sci_arttext.

Barnett, H. y Hunter, B. (1999). Ilustrated general of imperfect fungi. Fourth edition. The American phytopathological society. Pilot knob rodal, St Paul, Minnesota, USA.

Castaño-Zapata, J. (1986). Prácticas de laboratorio de fitopatología. Escuela agrícola panamericana. Departamento de protección vegetal. Zamorano, Honduras.

Guzmán, C. y Campos, C. (2004). Indicadores de contaminación fecal en biosólidos aplicados en agricultura. Revista Universitas Scientiarum, enero-junio, año/vol. 9, $\mathrm{N}^{\circ}$ 001. Pontificia Universidad Javeriana, Bogota, Colombia. Red de revistas científicas de America Latina y el Caribe, España y Portugal. Universidad Autonoma del Estado de Mexico. [Documento en línea]. Disponible en: http://redalyc.uaemex.mx/redalyc/pdf/499/49990107.pdf.

Sergueichuck, M. (1986). Guía metodológica para clases prácticas de microbiología.Universidad Nacional Autónoma de Nicaragua. Facultad de Ciencias Agropecuarias. Managua, Nicaragua.

Standard Methods for the examination of water and wastewater (2005)

Reyes F., Suarez A., Campos N. y Gómez M. (2006). Biodegradación del organoclorado-Aldrín a partir de cepas aisladas de un consorcio bacteriano aeróbico de la Cienaga Grande de Santa Marta. Resumenes de ponencias, "Los humedales, salvavidas contra la pobreza". Día mundial de los humedales, Ramsar. [Documento en línea]. Disponible en: http://www.ramsar.org/pdf/wwd/6/wwd2006_rpts_colombia01.pdf

Nexo Revista Científica / Vol. 29, No. 01, pp. 22-28 / Junio 2016 


\section{SEMBLANZA DE LOS AUTORES}

Luisa F. Durán-Acosta: Obtuvo el título de Profesora Especialista en Biología en la Universidad Pedagógica Experimental Libertador, Instituto Pedagógico "Rafael Alberto Escobar Lara", Maracay, Estado Aragua en la República Bolivariana de Venezuela. Desarrolló sus estudios de maestría en Ciencias Ambientales en la Universidad Nacional de Ingeniería, Nicaragua. Ha desarrollado estudios de investigación en el área de anatomía vegetal. Se desempeña como analista ambiental de aguas en el laboratorio ambiental perteneciente al Ministerio del Poder Popular de Ecosocialismo y Aguas de la República Bolivariana de Venezuela.

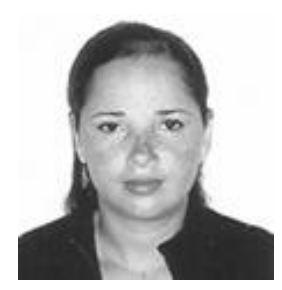

Marvelis J. Ladera-Hernández: Se tituló de Profesora Especialista en Biología en la Universidad Pedagógica Experimental Libertador, Instituto Pedagógico "Rafael Alberto Escobar Lara", Maracay, Estado Aragua en la República Bolivariana de Venezuela. Desarrolló sus estudios de maestría en Ciencias Ambientales en la Universidad Nacional de Ingeniería, Nicaragua. Ha desarrollado estudios de investigación en el área de anatomía vegetal. Se desempeña como técnico ambiental en el Ministerio del Poder Popular de Ecosocialismo y Aguas de la República Bolivariana de Venezuela. 